\section{MUSTH IN FEMALE ASIAN ELEPHANT}

\author{
Debabrata Swain ${ }^{1}$ and L.A.K. Singh ${ }^{2}$
}

Similipal Tiger Reserve, Baripada, Orissa 757002, India. Email: ${ }^{1}$ bid_simitig@sancharnet.in, ${ }^{2}$ bid_lashvini@sancharnet.in

According to the census carried out in May 2002, Similipal forests $\left(20^{\circ} 17^{\prime}-22^{\circ} 34^{\prime} \mathrm{N} ; 85^{\circ} 40^{\prime}-87^{\circ} 10^{\prime} \mathrm{E}\right)$ of Orissa, harbour 512 elephants consisting of 96 males, 283 females, 133 juveniles and calves, and five whose sex could not be identified. Only one makhna, the tusk-less male, was in the record. In a compilation of information on elephants of Similipal (Srivastava \& Singh, 2001) there has been no specific mention about musth condition in females of Similipal, although specific mention has been about musth in male elephants (Prusty \& Singh, 1995). In the present note, an observation of musth-like secretion in a female elephant is reported from Similipal.

On 28 July 2002, the first author sighted a group of 14 elephants at Devasthali in southern Similipal. The group consisted of eight adult females, five calves and one juvenile male. It was $1800 \mathrm{hr}$ and the sun was about to set. The elephants were grazing in the grassland just beyond the trench of the beat house-cum-watch tower. For closer observation of these elephants, a handful of common salt was sprinkled on the outer beam of the trench. Within minutes elephants gathered outside the trench and started taking the soil mixed with the salt and they were just $2.5 \mathrm{~m}$ away from DBS.

One of the female elephants, the biggest among the females and possibly a matriarch, had secretion of musth fluid from both the temporal glands. The sex of the elephants was confirmed after ruling out the possibility of the elephant being a makhna, the tusk-less male. The elephant had a calf at her heel. The calf was over six months old and was taking a suckling-posture occasionally. The female was 40 years old and appeared robust in build. She seemed to mingle with other elephants in the group without any noticeable abnormal behavior. It was not known if the female was in a state of estrous.

In the case of African elephants both male and female are known to come in musth (Chandrasekharan \& Cheeran, 1996). Musth in male Asian elephant is also well known. Reports of musth in female Asian elephant are rare. Sarma (2001) came across two female elephants "in musth-like condition where moderate amounts of clear temporal secretion were seen and a somewhat arrogant behaviour was noticed". One of these was 'Manimala' belonging to Dibyalochan Das of Dhupadhara. When observed with musth secretion, Manimala was in a pronounced state of estrous. The other female elephant was 'Rahdoi' belonging to L.K. Hazarika of Tangla. Sarma (2001) and Pathak (1991) also state that on rare occasions musth is observed in female Asian elephants.

The present observation from the wild in Similipal adds to the record of musth in female Asian Elephant in the wild, and the absence of any noticeable behavioural abnormality is noteworthy.

\section{References}

Chandrasekharan, K. and J.V. Cheeran (1996). Use of antiandrogen in controlling musth in captive elephants. Zoos' Print 11(4): 25-26.

Pathak, S.C. (1991). The elephant. Journal of the Assam Veterinary Council 1: 65-68.

Prusty, B.C. and L.A.K. Singh (1995). Male-male aggression in Asian elephant observed in Similipal Tiger Reserve, Orissa. Indian Forester 121(10): 902-908.

Sarma, K.K. (2001). Musth in Asian Elephant. Central Zoo Authority, New Delhi, 61pp.

Srivastava, S.S. and L.A.K. Singh (2001) (Compilers). Elephants in Similipal: History, Status, Issues, Techniques and Biological Notes on Elephants Volume 1. Similipal Tiger Reserve, Baripada, Mayurbhanj, Orissa, 200pp. 